\section{GÉNESIS DE LA COMPRENSIÓN EXPERIENCIAL DEL OCIO EN LA MODERNIDAD TARDÍA: TRANSFORMACIONES DEL CONCEPTO DE VIVENCIA}

\author{
Jaime Cuenca Amigo \\ Instituto de Estudios de Ocio \\ Universidad de Deusto \\ C/ Avda. de las Universidades 24 \\ 48007 Bilbao (Vizcaya) \\ jaime.cuenca@deusto.es
}

\section{GENESIS OF THE EXPERIENTIAL COMPREHENSION OF LEISURE IN LATE MODERNITY: TRANSFORMATIONS OF THE CONCEPT OF LIVED EXPERIENCE}

\begin{abstract}
Over the last decades an experiential comprehension of leisure has spread in Leisure Studies. In order to correctly understand all implications of this theoretical paradigm, the deep change in the concept of experience that it represents has to be taken into account. This article tries to contribute to this task by pointing out the transformations of the notion of "lived experience" ("vivencia"), from its origins to the current understanding. With this purpose, we will collect the successive functions the concept plays in different theoretical discourses, as well as its insertion in the general linguistic use, which is indicative of the changes at the social practices level. The article stays within a clear spatial and temporal framework, which refers to Germany between the 30s of the $19^{\text {th }}$ century and the same decade of the next century, since this is the arena where the main discussions that prepare the current sense of the concept of lived experience took place.
\end{abstract}

KEY WORDS: Experience; lived experience; Leisure Studies; Philosophy of Life; youth movement; late modernity.

\section{INTRODUCCIÓN}

Un amplio acuerdo entre los investigadores cifra en tres las principales líneas de definición del ocio: tiempo, actividad y actitud (Walsmley y Jenkins, 2003, p. 279). Para referirse a esta última línea es común usar también las expresiones "estado mental" o "experiencia subjetiva". Las definiciones en torno a los conceptos de tiempo (libre) y actividad pertenecen a la orientación objetiva representada por la Sociología del Ocio. En esta primera fase, los Estudios de Ocio están estrechamente vinculados a la Sociología ocupacional o del trabajo (Riesman, 1950; Friedmann, 1958; Anderson, 1961; Dumazedier, 1962; Smigel, 1963; Parker, 1976). Todas estas investigaciones sociológicas, que cons-
RESUMEN: En las últimas décadas se ha asentado en los Estudios de Ocio una comprensión experiencial del fenómeno del ocio. Para entender cabalmente las implicaciones de este paradigma teórico debe tenerse en cuenta el profundo cambio del concepto de experiencia que este supone. El presente artículo trata de contribuir a esta tarea recorriendo las transformaciones de la noción de vivencia, desde sus orígenes hasta el momento en que se asienta su comprensión actual. Con este propósito, se recogerán las sucesivas funciones que cumple el concepto en los discursos teóricos, así como su inserción en el uso lingüístico general, indicador de los cambios a nivel de las prácticas sociales. Se parte de una clara delimitación espacial y temporal, que refiere a Alemania entre los años 30 del siglo XIX y la misma década del siglo siguiente, puesto que es éste el escenario de los principales debates que preparan el significado actual del concepto de vivencia.

PALABRAS CLAVE: Vivencia; experiencia; Estudios de ocio; Filosofía de la vida; movimiento juvenil; modernidad tardia.

tituyen el primer corpus teórico consistente de los Estudios de Ocio, se basan principalmente en un análisis de las prácticas y de los usos del tiempo. Con distintos matices, comparten una definición objetivista del ocio como tiempo libre 0 , con mayor precisión, como el conjunto de actividades practicadas en el tiempo liberado de las obligaciones.

En la década de los 70 se origina una segunda orientación en los Estudios de Ocio, que rechaza las aproximaciones exclusivamente objetivistas que se habían realizado hasta el momento y aboga por un giro hacia el sujeto. Se trata del acercamiento psicológico al fenómeno del ocio iniciado por Neulinger (1974) con su obra The Psychology of Leisure. Iso-Ahola (1980) publica el primer libro de 
texto de la disciplina, proponiendo la libertad percibida y la motivación intrínseca como condiciones fundamentales para que el sujeto experimente una vivencia de ocio. Otro autor influyente en este campo de investigación es Mihalyi Csikszentmihalyi, quien desarrollará el concepto de flow o experiencia óptima (Csikszentmihalyi, 1975, 1991). A las dos notas mencionadas añadirá el equilibrio entre el reto de la actividad y la destreza del sujeto. En general, desde esta perspectiva psicológica, se ha tratado de aprehender y categorizar la percepción del sujeto definiendo el ocio como una experiencia preparada por ciertas condiciones, dotada de determinadas cualidades y causante de numerosos beneficios (Tinsley \& Tinsley, 1986).

Aunque se ancla en última instancia en la ya citada obra pionera de Neulinger The Psychology of Leisure (1974), puede afirmarse que el paradigma de investigación que concibe el ocio como experiencia no alcanza su máxima extensión en los Estudios de Ocio hasta la última década del pasado siglo. En 1994, Lee, Dattilo y Howard hablan ya del paso de un paradigma objetivo a otro subjetivo y constatan el abundante uso de la expresión "experiencia de ocio" en la bibliografía del momento. Cuatro años después, la revista Journal of Leisure Research dedicaba un número monográfico a la comprensión del ocio como experiencia. Numerosos investigadores han estudiado la naturaleza multidimensional (Jennings, 1997; Ritchie \& Hudson, 2009; Volo, 2009), multi-fase (Killion, 1992; Ooi, 2005; Borrie \& Roggenbruck, 2001) y dinámica (Hull, Stewart \& Yi, 1992; Jonas, 2007) de la experiencia de ocio. Esta línea de definición del ocio es introducida en la investigación en lengua castellana por el Instituto de Estudios de Ocio de la Universidad de Deusto. A la hora de verter al castellano este paradigma más reciente en los Estudios de Ocio se opta por los términos "experiencia" y "vivencia", que se usan indistintamente (Cuenca Cabeza, 2000, 2006; San Salvador del Valle, 2000; Amigo, 2000; Goytia, 2008), salvo muy contadas excepciones (Monteagudo, 2008).

Este uso indistinto de los términos "vivencia" y "experiencia" para conceptualizar el fenómeno del ocio en casteIlano revela una serie de rasgos constitutivos de la actual noción del ocio que quedan quizá menos explícitos en la bibliografía anglosajona (la cual maneja únicamente el término "experience"). Poco importa insistir en la comprensión experiencial del ocio en la actualidad si no se toma conciencia de las notas específicas que determinan el concepto de experiencia en este paradigma, alejándolo de concepciones anteriores y vinculándolo con la carga semántica que arrastra consigo el término "vivencia". El presente artículo se propone contribuir a esta toma de conciencia recorriendo los cambios y continuidades en el significado del concepto de vivencia, desde sus mismos orígenes hasta el momento en que se asienta su comprensión actual. Se atenderá a las sucesivas funciones que cumple el concepto en los discursos teóricos, así como a su inserción en el uso lingüistico general, indicador de los cambios a nivel de las prácticas sociales. La aparente ambición de estas intenciones queda matizada por una clara delimitación espacial y temporal, que refiere a Alemania entre los años 30 del siglo XIX y la misma década del siglo siguiente. Este marco social y este lapso histórico formaron la arena en que se completaron las mutaciones que han hecho de la vivencia el concepto que hoy conocemos y que resulta imprescindible para la comunidad hispanohablante de los Estudios de Ocio.

\section{Primeros significados del concepto de Vivencia}

El término alemán "Erlebnis" es sustantivo procedente del verbo "erleben", forma que enfatiza el uso transitivo de "leben", vivir. Fue Ortega y Gasset quien propuso traducir "Erlebnis" en castellano por la palabra "vivencia" que quiere guardar el mismo parentesco y la misma distancia con respecto a "vida" como el alemán respecto a "Leben"1. En vez de "Erlebnis", en alemán se usa también a menudo con idéntico significado la forma sustantivizada del verbo ("Erleben").

Según Gadamer (1977, 96), el verbo "erleben" significaba originalmente "estar todavía en vida cuando tiene lugar algo" y su tardía derivación "Erlebnis", en su sentido menos preciso, puede hacer referencia sin mayor determinación a los contenidos de la propia vida, del mismo modo en que se usa el participio del verbo "vivir" en castellano cuando se subraya su aspecto transitivo (como en "lo que uno ha vivido", por ejemplo). Los primeros usos documentados del término en alemán señalan precisamente en esa dirección. Gadamer $(1977,96)$ considera que el testimonio más antiguo se encuentra en una carta de Hegel, donde dice "meine ganze Erlebnis" ("toda mi vivencia") para referirse a un tiempo de viaje. Cramer recoge el que probablemente 
sea el primer intento de definición del término, realizado por W. T. Krug (sucesor de Kant en la cátedra de Lógica y Metafísica en la Universidad de Königsberg) en su Diccionario enciclopédico de la última literatura e historia de la Filosofía (1838):

Se llama vivencia a todo aquello que uno mismo ha vivido (percibido, contemplado, pensado, querido, hecho o dejado hacer). Tales vivencias son por tanto el fundamento de la propia experiencia, cuando uno sabe extraer de ellas los resultados apropiados (citado en Cramer, 1972, 705)².

En este sentido, como se ve, la vivencia (Erlebnis) aparece en una relación con la experiencia (Erfahrung) análoga a la que guardan las premisas implícitas de una operación intelectiva con su producto, o las fuentes diversas y confusas del aprendizaje con su formulación durable en la conciencia. Cuando este par de conceptos se oponen, la articulación sistemática y la cristalización en saberes 0 destrezas siempre cae del lado de la experiencia; la vivencia, en cambio, conserva cierto grado de inmediatez que no se deja reducir a significado. El núcleo de esta oposición se mantiene aun cuando el sentido que se atribuye al término "vivencia" presenta una determinación mayor. Así ocurre cuando trata de distinguirse la vivencia del flujo general de "lo que se vive"; distinción que acabó imponiéndose en el uso generalizado (Cramer, 1972, 703).

Este uso asentado del término "vivencia" refiere a aquello que se experimenta de un modo inmediato, pero que no desaparece en el flujo indistinto y trivial de lo que vivimos, sino que se vincula, por su relevancia, a la totalidad de sentido de nuestra propia vida. Desde esta perspectiva, puede hablarse de una vivencia como puede hablarse de una experiencia, pero la diferencia radica en que la segunda recibe su concreción, a partir de Kant, de una construcción del sujeto, es decir, de una operación por la cual ciertas estructuras subjetivas median entre la materia de lo vivido y el significado que ésta adquiere, mientras que la vivencia reclama para sí una concreción y relevancia previas a toda construcción: "En este sentido, pertenece a la esencia de la vivencia mantener su destacada inmediatez y no disolverse en aquello que pueda determinarse como su significado" (Cramer, 1972, 703) ${ }^{3}$.

Este cruce entre inmediatez y relevancia para el sentido de la vida entera parece darse paradigmáticamente en la vivencia de la religión, el amor y el arte (Cramer, 1972, 703). De ahí que pueda señalarse una prehistoria romántico-panteísta del concepto de vivencia que discurre por términos vinculados a esos campos y semánticamente cercanos (tales como "sentimiento", "gusto" o "interioridad"). No en vano, como recuerda Gadamer, el concepto de la vida, estrechamente vinculado al de vivencia, constituye el fundamento metafísico del idealismo alemán, crítico con el racionalismo de la Ilustración (Gadamer, 1977, 99). Pero esta resonancia casi religiosa del término, como se ha visto, no está presente en los primeros usos documentados. Será R. H. Lotze (1817-1881) quien colabore en la extensión entre la burguesía ilustrada alemana de un significado más cercano al que describimos ahora, tomando el término como fundamento de su irracionalismo especulativo (Cramer, 1972). Aspiraba así a remediar la pérdida de sentido que habrian experimentado las condiciones de vida del individuo al ser interpretadas desde el punto de vista materialista de las ciencias naturales. De este modo se anuncia ya el significado definitivo, puesto que "vivencia es un concepto típicamente post-hegeliano y crítico, al mismo tiempo, con las pretensiones de las ciencias naturales del siglo XIX" (Cramer, 1972, 706) ${ }^{4}$.

El sentido atribuido por Lotze a "vivencia" prepara la función central que le asignará Dilthey (1833-1911) en su intento por formular un método propio para las ciencias del espíritu que las distinga claramente de las de la naturaleza, y en esta misma línea de recepción se encuadra la importancia del término en la Fenomenología de Husserl (1859-1938). En ambos casos, se busca disputar la hegemonía en la moderna teoría del conocimiento a una comprensión mecanicista de experiencia, que concibe todo contenido de la conciencia como construido sobre los elementos últimos de la sensación. El interés, por tanto, es ante todo epistemológico. Sin embargo, desde comienzos del siglo $X X$, se da una súbita expansión del uso de "vivencia", unida a la adopción de un significado que va más allá de la mera consideración metodológica. Éste se convierte de pronto en el concepto filosófico de moda y se sitúa en el centro mismo de la Filosofía de la vida y de la Weltanschauung (cosmovisión) del primer tercio del siglo XX (Cramer, 1972, 709).

En la Alemania de entonces la vivencia no encarna sólo el intento por responder al predominio de las ciencias naturales y su concepto de experiencia en el campo epis-

ARBOR Vol. 188754 marzo-abril [2012] 315-325 ISSN: 0210-1963

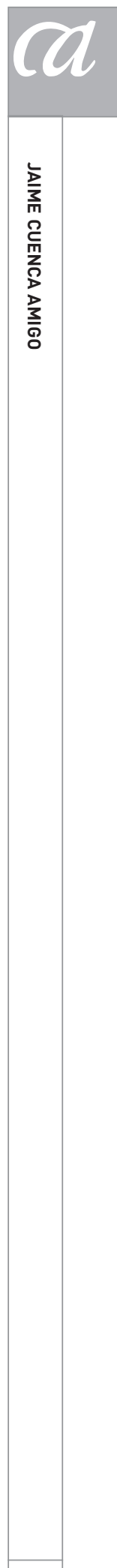


temológico, sino que es ya el lema de un vasto movimiento espiritual opuesto al racionalismo 0 , mejor, al ascetismo racionalista, tanto en la teoría como en la práctica. Como afirma Gadamer (1977, 99): "La irrupción del movimiento juvenil frente a la cultura burguesa y sus formas de vida estuvo bajo este signo [el de la vivencia]". Lo que aglutina en torno a sí el concepto de vivencia en la Alemania del primer tercio del $X X$, tanto como categoría epistemológica como en cuanto eslogan de masas, es una profunda reacción frente a la triunfante modernización del saber, la economía y la sociedad; en pocas palabras: una rebelión de la burguesía contra sí misma (Krockow, 1990, 28ss).

\section{LA VIVENCIA REDENTORA}

Ya desde finales del siglo XIX empezaron a aparecer en Alemania signos de una posición antiburguesa, sostenida por la propia burguesía, que no hizo sino radicalizarse en las siguientes décadas. El primer movimiento que da una expresión teórica a este malestar es la Filosofía de la vida (Lebensphilosophie) que tanto éxito alcanzó en el cambio de siglo. Sinteticemos algunas de las posiciones más divulgadas de la Filosofía de la vida para determinar los rasgos principales del clima espiritual "antiburgués" y el lugar que en él ocupaba el concepto de vivencia. Krockow $(1990,30)$ resume su mensaje central en la siguiente oposición:

Se contraponen dos tipos fundamentales: uno que calcula conforme a fines, para el que todo se reduce a la calculabilidad y, con ello, al dominio de las cosas y que sólo reconoce como real lo que es mensurable y calculable, y otro que busca el contacto inmediato con las esencias y el ser. Al primer tipo le está vedado el acceso a la realidad, porque comprende todo de manera relacional, en una calculadora remisión a "leyes", escalas, axiomas generales; al final quedan sólo relaciones abstractas. Esto puede visualizarse por ejemplo en las ciencias naturales de la edad moderna, pero cabe señalar también a la moderna mentalidad económica ${ }^{5}$.

Como puede verse, los sistemas metódicos de acción racional conforme a fines se oponen aquí a una cierta forma de vida que abriría un acceso inmediato al ser. En este contexto, la vivencia se percibía precisamente como esa puerta privilegiada de conocimiento de la realidad: así,
Max Scheler, el principal responsable de la extensión de un cierto intuicionismo irracionalista por aquellos años, propugnaba una filosofía que partiera de la "vivencia del contenido esencial del mundo" (Cramer, 1972, 709). De hecho, oposiciones como la descrita arriba fueron muy populares en Alemania en las dos primeras décadas del siglo XX, hasta el punto de que llegaron a fundar la defensa ideológica de los intereses nacionales durante la I Guerra Mundial.

Este clima intelectual, que puede englobarse con mayor o menor exactitud en la Filosofia de la vida y que presta a la vivencia su acento más religioso, encuentra su cauce práctico en el movimiento juvenil (Jugendbewegung), activo por toda Alemania a través de un gran número de asociaciones desde comienzos del siglo XX hasta los años 30. Surgido principalmente en las grandes ciudades alemanas entre los hijos de la burguesía más modesta, el movimiento juvenil canalizó durante un tiempo el descontento de toda una generación que se vio inmersa, de un modo abrupto, en formas de organización social plenamente modernas. Krockow $(1990,33)$ no duda en imputar su éxito al rápido paso de Alemania desde el Estado agrario al capitalismo avanzado. Su espíritu era inevitablemente nostálgico, como muestran las muchas marchas a fortalezas y castillos abandonados por todo el pais, que acabaron convertidos, en muchos casos, en hospedajes para diversas organizaciones juveniles ${ }^{6}$. En el seno de esta nostalgia grupalmente cultivada, la vivencia, comprendida en un sentido romántico-panteísta, ejercía de talismán y refugio frente a las amenazas de una experiencia social sometida a una estricta racionalidad teleológica o, en otros términos, al ascetismo intramundano de la profesión. Así expresa Krockow $(1990,31-32)$ el espíritu del movimiento juvenil:

Se mueve por el anhelo de una forma de vida muy determinada, que los adultos del momento no podian ofrecer: parte del anhelo de una vivencia del "nosotros" que ponga a los individuos en una relación inmediata entre sí. Quiere una agrupación de la honestidad, de la "contemplación de esencias" ininterrumpida y mutua; en vez de la "sociedad" especializada y conforme a fines, una "comunidad en si" desinteresada y sin condiciones. El peso de esta postura cae consecuentemente del lado de la emoción irracional, por contraposición a la racionalidad conforme a fines y la calculabilidad?. 
La vivencia aparecía así, a los ojos del movimiento juvenil y la Filosofía de la vida, como el núcleo de una forma de existencia que se enfrenta a la sociedad racionalizada y la economía moderna.

\section{LA INFLEXIÓN DECISIONISTA}

Este clima espiritual que hemos descrito, pronto se deslizaría hacia derroteros menos inofensivos. Así, las ideas de la "comunidad en sí" y del Führer (caudillo), propias del movimiento juvenil (Krockow, 1990, 35), se cargarían de resonancias militaristas tras la I Guerra Mundial. De hecho, muchos miembros de antiguas asociaciones juveniles y de estudiantes reencontrarian la vida comunitaria de preguerra en grupos paramilitares como los Freikorps o los Cascos de acero (Stah/helm), de ideología ultranacionalista y antidemocrática. Por el lado teórico, se advierte también una clara continuidad entre el ambiente irracionalista de comienzos de siglo y la llamada "Revolución conservadora", que acabaría dando, en algunos casos, notorios partidarios al Tercer Reich. Krockow $(1990,36)$ no duda en establecer un paralelismo entre "el desplazamiento de la Filosofía de la vida por la de la existencia o la absorción del movimiento juvenil por parte del nacionalsocialismo"8.

Krockow analiza los puntos en común que se ponen de manifiesto en la obra de Ernst Jünger, Carl Schmitt y Martin Heidegger: los conceptos de lucha, decisión y determinación, respectivamente, tienen en cada caso una función análoga que permite hablar de un "decisionismo" común a los tres. Krockow describe la Filosofía de la vida y el movimiento juvenil (también el círculo de Stefan George) como una suerte de neo-romanticismo, cuya más consecuente continuación sería precisamente el decisionismo de Jünger, Heidegger y Schmitt, que se convierte así en "el Romanticismo pensado hasta el final" (Krockow, 1990, 88). Ahora bien, una filiación tan directa dista de ser evidente.

El propio Krockow $(1990,82)$ reconoce que la relación entre Romanticismo y decisionismo es bastante oscura, lo que no le impide tratar de proyectar sobre éste último las críticas del propio Schmitt al Romanticismo político. El principal escollo son las categorias de la estetización y la privatización. Schmitt arremete contra la absolutización de lo estético propia del Romanticismo: por un lado, ésta consigue deformar todos los ámbitos del espíritu, impidiendo la verdadera toma de decisiones políticas, morales, religiosas o de cualquier otro tipo; por otro lado, va unida a una exaltación de los sentimientos privados que somete al individuo a una carga antes repartida entre diversos estamentos del cuerpo social (Krockow, 1990, 87). La insistencia sobre el cultivo de la interioridad como sede de las vivencias estéticas y refugio del individuo frente a las opresoras convenciones sociales es un tema central en el Romanticismo. Krockow está en lo cierto al advertir sus resonancias en la Filosofía de la vida y el movimiento juvenil. Sin embargo, los "decisionistas" de los que se ocupa se caracterizan precisamente por repudiar tanto la opresión de las convenciones sociales modernas (que son fuente de inautenticidad: el man de Heidegger), como la escapada estetizante de las mismas. Los intentos de Krockow por conciliarles con la estetización y privatización románticas son rebuscados y poco convincentes, y no logran sobreponerse a la firmeza de las palabras de Schmitt que él mismo cita.

Si subrayamos aquí estas diferencias entre el neo-romanticismo de pre-guerra y la doctrina decisionista de los años 20 y 30 no es por un mero prurito de rigor academicista, sino porque son reveladoras de una transformación de la vivencia (en la teoría y en la práctica) que nos parece crucial. En efecto, si la Filosofía de la vida promovió esa concepción estetizante y cuasi-panteísta de la vivencia que hemos descrito arriba, el decisionismo la rechazó, pero lo hizo añadiendo ciertas reveladoras notas a su condena. Los decisionistas reprueban la vivencia por trivial y mercantilista, algo que no parece encajar en los rasgos que hasta ahora le hemos atribuido. De hecho, como se ha visto, en la Filosofía de la vida la vivencia aparece como enfrentada a las triviales convenciones sociales y al modo de vida productivista burgués. Así pues, nos interesa aquí no tanto qué pensaban los decisionistas, sino contra qué pensaban, y qué pueda decirnos este blanco de sus ataques sobre la transformación de la vivencia en el período de entreguerras.

A este respecto es muy significativo un apunte que hace Carl Schmitt $(1991,111)$, casi de pasada, en una conferencia dictada en Barcelona en 1929:

Con el siglo XIX lo que aparece es la era en la que se establece una conexión al parecer híbrida e imposible entre tendencias estético-románticas y económico-técnicas. En realidad el romanticismo del XIX -si no queremos utilizar

ARBOR Vol. 188754 marzo-abril [2012] 315-325 ISSN: 0210-1963

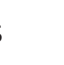


ese término algo dadaísta del romanticismo a la manera romántica, como vehículo de confusiones- no significa sino la etapa intermedia de lo estético entre el moralismo del XVIII y el economicismo del XIX, una mera transición que se logró introduciendo la estética en todos los dominios del espíritu, y por cierto que con gran facilidad y éxito. Pues el camino que va de la metafísica y la moral a la economía pasa por la estética, y la vía del consumo y disfrute estéticos, todo lo sublime que se quiera, es la más cómoda y segura para llegar a una "economificación" general de la vida espiritual y a una constelación del espíritu que halle las categorías centrales de la existencia humana en la producción y el consumo. En el ulterior desarrollo espiritual el esteticismo romántico se pondrá al servicio de lo económico y constituirá un fenómeno concomitante típico.

La seguridad de Schmitt evidencia que algo ha cambiado en la percepción pública de la vivencia entre este pasaje y el clima espiritual que resumíamos arriba con una cita de Krockow. Antes de la I Guerra Mundial, la vivencia estética era todavía un escape a la calculabilidad promovida por la economía burguesa; en 1929, en cambio, la extensión de la mentalidad vivencial romántica podía concebirse ya como el medio necesario para el triunfo total de la economía. Schmitt es tajante: da igual cuán sublime se represente "la vía del consumo y disfrute estéticos", es decir, qué resonancias místicas o panteístas quieran escucharse en la vivencia estética, lo cierto es que su extensión sienta las bases para la economificación de la vida entera.

Por lo que parece, a finales de los años 20 podía afirmarse algo así en una conferencia sin necesidad de entrar en mayores justificaciones: el público debía de hallarse predispuesto, por su experiencia cotidiana, a aceptar el vínculo entre vivencia estética y rentabilidad económica; el mismo vínculo que apenas diez años antes se hubiera rechazado con indignación. ¿Qué ha ocurrido, entonces, en ese tiempo? ¿Qué cambiaron los años 20 en la experiencia cotidiana de las metrópolis europeas? La respuesta debemos buscarla en la expansión de una nueva cultura del ocio de masas.

\section{LA VIVENCIA DEL OCIO DE MASAS}

Una vez superadas las secuelas más sangrantes de la Gran Guerra, el clima espiritual de las principales metrópolis oc- cidentales comenzó a distanciarse significativamente del que imperaba en los años de preguerra. El desengaño sufrido por la generación combatiente condujo al abandono de los valores propios del ascetismo profesional burgués. Este abandono, sin embargo, no condujo de vuelta al heroísmo neo-romántico de pre-guerra, con su concepción mística de la vivencia. La vida cotidiana pronto se vio caracterizada por una abundancia material desconocida hasta entonces, lo que trajo consigo nuevas formas de rebelión ante el ascetismo burgués tradicional. Así, Daniel Bell afirma que "la verdadera revolución social en la sociedad moderna se produjo en la década de 1920, cuando el aumento de la producción en masa y el elevado consumo comenzaron a transformar la vida de la misma clase media". Fue entonces cuando "la ética protestante como realidad social y estilo de vida de la clase media fue reemplazada por un hedonismo materialista, y el temperamento puritano por un eudemonismo psicológico" (Bell, 1977, 81).

La voluntad de ruptura con la vieja mentalidad burguesa y la buena situación económica de los años 20 hicieron que se desarrollara rápidamente una nueva cultura urbana, caracterizada sobre todo por la extensión inédita de ciertas formas de ocio: algunas nuevas y otras ya conocidas, pero reservadas hasta entonces a las élites. Esta cultura del ocio masivo, pese a los cambios cuantitativos y cualitativos que han traído las décadas transcurridas, es todavía la que podemos considerar definitoria de nuestro presente histórico. Puede decirse que las condiciones actuales de la vivencia de ocio encuentran su raíz en esta cultura emergente en la época de entreguerras. Así se aprecia, por ejemplo, en el campo de los medios de comunicación de masas que vivían entonces un momento de ebullición: medios maduros convivían con otros que estaban en desarrollo o en las etapas iniciales de su experimentación técnica. En el marco del vasto cambio de mentalidad en las poblaciones urbanas, los medios masivos se convirtieron en aquellos años en los principales proveedores de entretenimiento. Comenzaremos por la extensión de los medios de comunicación de masas, un breve repaso por el panorama de estas formas de ocio urbano que transformaron, de un modo perdurable, la experiencia cotidiana en las grandes urbes.

La prensa periódica era un medio que gozaba ya de plena madurez en el primer tercio del siglo XX. Así, por ejemplo, en 1926 había 3.812 periódicos en Alemania, 112 de los cuales se publicaban diariamente en Berlín (Gumbrecht, 
2004, 205). Estas cifras no son sino el resultado de un largo proceso que comenzó a mediados del siglo anterior y obtuvo su principal impulso con la invención de la linotipia. Sin embargo, es en los años 20 cuando la masiva demanda de prensa escrita consolida una figura que le está indisociablemente unida: la del periodista. Su imagen pública aparece entonces definida por la decisión, la velocidad y la constante estimulación nerviosa, significada por el consumo de café y cigarrillos que le atribuía la imaginación popular (Gumbrecht, 2004, 202-204).

Estos rasgos no dejan de ser relevantes, porque parecen facultar al periodista, a ojos de sus lectores, para atrapar la experiencia cotidiana de un modo nuevo, situado por encima de la percepción superficial, pero sin llegar a una profunda interpretación de los hechos. Según recuerda Gumbrecht, en la Alemania de entonces se aludía crecientemente a este modo de experiencia con el término "Erleben" o "Erlebnis", es decir, "vivencia", sumando así a la palabra un uso inédito y bien distinto de los anteriores. De hecho, uno de los periodistas de mayor prestigio, Egon Erwin Kisch, era denominado precisamente como "der Erleber" ("el vivenciador") (Gumbrecht, 2004, 203). El periodista se convierte en un profesional capaz de experimentar vivencias y proveer con ellas a sus lectores. De este modo, las noticias y reportajes sobre los temas más diversos se unen a la ya asentada literatura de folletín como contenidos destinados al entretenimiento de la población urbana.

En comparación con la prensa escrita, la radio estaba aún en los años 20 en los comienzos de su expansión, la cual fue, no obstante, mucho más rápida que la de aquella. En 1922 se vendieron cien mil aparatos de radio en Estados Unidos, pero apenas tres años más tarde había ya cinco millones y medio (Briggs; Burke, 2002, 183). En 1926 su penetración permitía que ciertas emisiones se convirtieran, ellas mismas, en un evento celebrado y recordado: así ocurrió, por ejemplo, con el combate de boxeo que tuvo lugar en Filadelfia el 23 de septiembre de aquel año, entre Jack Dempsey y Gene Tunney. Una audiencia estimada de 15 millones de radioescuchas en América y Europa siguió la retransmisión en directo, lo que da una idea de la atracción que ejercía la radio como canal de entretenimiento sobre las masas urbanas (Gumbrecht, 2004, 76). Las expectativas de negocio condujeron rápidamente a la concentración: así, si en 1926 las cadenas sólo representaban un 6,4\% del total de emisoras de radio en EE.UU., cinco años más tarde ya eran el 30\% (Briggs; Burke, 2002, 184). Los radioaficionados que levantaron el medio pronto fueron remplazados por emisoras profesionales, especializadas en la provisión de noticias y programas de variedades.

El caso de la televisión, en fase experimental durante los años 30, corrobora la progresiva aceleración en la implantación de nuevos medios. Si la radio necesitó 35 años desde el descubrimiento físico que la posibilita hasta su comercialización, la televisión precisó de sólo 12 años para el mismo proceso (Gutiérrez Espada, 1979, 31). Desde luego, no puede decirse que en este primer momento llegara a ejercer un influjo apreciable sobre una audiencia masiva, pero sí hizo valer su presencia con espectacularidad en ciertas ocasiones señaladas. Los Juegos Olímpicos de Berlín en 1936 se convirtieron en el primer gran evento en la historia mundial que fue cubierto por la televisión; si bien sólo un público selecto pudo comprobarlo en unos pocos teatros de Alemania (Gumbrecht, 2006, 148). Sin embargo, no hay duda de que la mayor presencia mediática de aquellos juegos se dio a través del cine, gracias al documental Olympia (1938) de Leni Riefenstahl.

En efecto, en los años 20 y 30 el cine era, pese a su breve historia, el medio del momento. Su implantación en las grandes ciudades fue fulminante. Por poner un ejemplo: entre 1913 y 1932 el número de cines en Liverpool pasó de 32 a 69, y se calcula que en este último año cuatro de cada diez personas acudian al cine una vez por semana, y una de cada cuatro, dos veces (Briggs; Burke, 2002, 192). El nuevo medio no tenía rival como proveedor de entretenimiento: así, tras el auge de los años 20, el teatro de revistas y variedades se reveló como un género de carácter transicional, destinado a desaparecer bajo la progresiva extensión de los palacios de cine (Gumbrecht, 2004, 219). En estos locales, la proyección se enmarcaba en un espectáculo de juegos de luces, coreografías y música en directo que transportaba a los espectadores a un mundo ilusorio de estética cuidadosamente diseñada. Con la introducción del cine sonoro a partir de 1926, las experiencias de los espectadores alcanzaban un nivel de inmersión inimaginable hasta entonces.

La forma intensificada y gratificante de experiencia que proporciona el cine se volvió rápidamente un elemento central en el modo de vida de la población urbana, mostrando su eficacia fuera de los palacios de cine. Así lo 
demuestra el surgimiento del fenómeno de las "estrellas": cantantes, actores, artistas o deportistas que se convierten en ídolos populares y modelos de vida. El caracteristico peinado de Rodolfo Valentino, por ejemplo, generaba cuantiosas ganancias a los productores de gomina para el cabello (Gumbrecht, 2004, 119), debido a los muchos admiradores que trataban de imitar la vida de su ídolo. Y no sólo la vida: están documentados varios intentos de suicido con motivo de la muerte de Valentino en 1926 (Gumbrecht, 2004, 120).

Quizá este ejemplo extremo pueda dar una idea de la eficacia combinada de los medios que hemos descrito hasta aquí. Sería un grave error de apreciación relegarla al mero ámbito del entretenimiento, como si éste se hallara desvinculado de la totalidad de la existencia individual. De hecho, el tumultuoso inicio del ocio mediático se enmarca en un cambio mucho más amplio. En los años 20 y 30 surge una nueva cultura urbana que se expresa, sobre todo, en la expansión de ciertas formas de ocio: el gusto por los bares y otros establecimientos de entretenimiento nocturno, unido a las primeras modas de música popular moderna (el jazz), la afición al deporte (con la creación de la Copa Mundial de Fútbol en 1929, por ejemplo) y el crecimiento del turismo (si bien todavía reservado a las clases más pudientes). Ya hemos comentado arriba cómo Daniel Bell percibe en estos procesos "la verdadera revolución social en la sociedad moderna". Pero éste no es sólo un juicio retrospectivo: muchos eran ya entonces conscientes de la importancia del cambio en curso y lo entendían como una transformación de los modos de experiencia, si bien añadiendo generalmente a esta constatación un juicio de condena, ya sea en el sentido de una pérdida de la autenticidad (Heidegger) o en el de una extensión general de la alienación (Horkheimer y Adorno).

El énfasis tradicional de la mentalidad burguesa sobre la forma racional, ascética y especializada de la experiencia decaía y a cambio emergían unas experiencias más inmediatas, gratificantes y dispersas. Éstas últimas se denominaban "vivencias", en la tradición neo-romántica descrita arriba, pero no aparecían ya como enfrentadas a la economía y la sociedad modernas. Al contrario: un complejo y creciente sector económico se ocupaba exitosamente de su provisión. Se trata de un punto de inflexión en la historia de las prácticas cotidianas de la sociedad moderna y los discursos que las interpretan, cuyas consecuencias seguimos experimentando a comienzos del siglo XXI.

\section{Conclusiones}

Comenzábamos este artículo recordando la comprensión experiencial del ocio, que impera claramente entre los investigadores especializados desde hace al menos dos décadas. Constatar la extensión de este paradigma, sin embargo, no sirve de mucho si no nos percatamos de que éste implica una severa transformación del concepto mismo de experiencia, con hondas raíces teóricas y prácticas. Aqui hemos tratado de recoger algunas dimensiones de esta transformación, atendiendo a los cambios en la noción de vivencia. Como decíamos al comienzo, el término ha acabado usándose como sinónimo de experiencia en el ámbito hispanohablante de los Estudios de Ocio. Sin embargo, esperemos haber podido aclarar que esta sinonimia no ha sido, ni mucho menos, evidente en varias fases de la evolución del concepto. Al contrario, en sus inicios, y durante bastante tiempo, "vivencia" se definió precisamente en oposición a "experiencia". Frente a las formas racionales, sistemáticas y abnegadas de praxis que ésta última recogía, la vivencia aparecía como el refugio de las emociones, la inmediatez y lo satisfactorio. La convergencia final de ambos conceptos denota un vasto cambio en las condiciones sociales de la experiencia cotidiana; si la convergencia se mantiene, debemos concluir que los efectos de este cambio también.

Es a estos efectos perdurables a los que refiere la expresión "modernidad tardía". Con ella no pretendemos tanto fijar un marco cronológico (que siempre tendría algo de arbitrario), sino señalar a un tipo de organización social. Por supuesto, la cuestión sobre la característica distintiva de la actual organización social frente a la que imperaba hace un siglo puede responderse -y se ha respondido- de muchas maneras: desde la "sociedad post-industrial" de Daniel Bell (1973) y los análisis de Inglehart (1990) sobre la extensión de valores "post-materialistas", hasta la "sociedad del riesgo" de Ulrich Beck (1986), la "modernidad reflexiva" (Beck; Giddens; Lash, 1994) o la "modernidad líquida" de Bauman (2002). Cada una de estas aportaciones teóricas hace hincapié legítimamente en uno $u$ otro rasgo de las sociedades contemporáneas para distinguirlas respecto de la fase temprana de la modernidad. Creemos que es razonable desde el punto de vista de la evidencia empírica y útil para futuras investigaciones entender por modernidad tardía precisamente aquella forma de organización social que no es hostil a la búsqueda de vivencias 
por parte del individuo, sino que, al contrario, precisa de ella y se ve sostenida en gran parte por ella. Esta forma de organización social comienza a advertirse, como hemos notado, en los años 20 del pasado siglo, cuando un vasto cambio en la mentalidad y las condiciones de vida extiende ciertas formas de ocio entre las poblaciones urbanas.

Lo que se percibía entonces como algo novedoso, surgido al amparo de un vasto cambio social, era el ocio como vivencia: una práctica tan gozosa y libre como el ocio clásico, pero caracterizada por su discontinuidad, espontaneidad y falta de sistema. Bajo las formas del jazz, el fútbol, la radio o el cine, la vivencia comenzaba a aparecérsele al individuo como una práctica que se distingue por su especial intensidad de la experiencia cotidiana, pero está inscrita en el centro mismo de esta cotidianeidad. No hay un marco ritual que la posibilite, ni se debe a un cultivo continuado de ciertas disposiciones, ni está separada de la praxis social por una distancia institucional. Es este modo de experiencia el que se vive y se percibe de modo paradigmático en las formas contemporáneas de ocio. Conviene ser conscientes de su especificidad.

\section{NOTAS}

1 No sin pedir excusas por un neologismo que considera tan malsonante como imprescindible, Ortega introduce su traducción en una nota al pie en su artículo "Sobre el concepto de sensación", publicado en tres entregas en los números de junio, julio y septiembre de 1913 de la Revista de Libros. Se trata en realidad de una recensión de la tesis doctoral de Heinrich Hoffmann, discípulo de Husserl, aunque Ortega aprovecha la ocasión para ilustrar al público español acerca de la Fenomenología en general (Ortega y Gasset, 2004, 634).

2 "Erlebnis heißt alles, was man selbst erlebt (empfunden, geschaut, gedacht, gewollt, gethan oder gelassen) hat. Solche Erlebnisse sind also die Grundlage der eigenen Erfahrung, wenn man dadurch richtige Ergebnisse zu ziehen versteht."

3 "So ist Erlebnis ein typisch nachhegelscher und zugleich den Anspruch der Naturwissenschaften des 19. Jh. kritisierender Begriff".

4 "Insofern gehört zum Wesen von Erlebnis, seine betonte Unmittelbarkeit zu behalten und nicht in dem aufzu- gehen, was sich als seine Bedeutung festhalten läßt."

5 "Zwei Grundtypen werden einander entgegengestellt: ein zweckhaft rechnender, dem auf die Berechenbarkeit und damit Beherrschung der Dinge alles ankommt und der als wirklich nur anerkennt, was meß- und berechenbar ist, und ein anderer, der unmittelbaren 'Wesens'- und Seinskontakt sucht. Dem ersten Typus ist der direkte Zugang zur Wirklichkeit verschlossen, weil er alles nur noch relational, im rechnenden Bezug auf allgemeine 'Gesetze', Maßstäbe, Axiome erfaßt; am Ende bleiben überhaupt nur abstrakte Relationen. Man kann das etwa an den neuzeitlichen Naturwissenschaften veranschaulichen, man kann aber auch auf die moderne Wirtschaftsgesinnung verweisen."

6 Uno de tales castillos, el de Ludwigstein, en Hessen, acoge hoy precisamente el Archivo del Movimiento Juvenil Alemán (Archiv der deutschen Jugendbewegung).

7 "Sie wird getragen von der Sehnsucht nach einer ganz bestimmten Lebensform, die die Erwachsenen der Zeit nicht bieten konnten: aus der Sehnsucht nach einem 'Wir'-Erleb-
Aceptado: 13 de julio de 2011 
nis, das die Einzelnen in ein unmittelbares Verhältnis zueinander stellt. Sie will einen Zusammenschluß der Direktheit, der ungebrochenen wechselseitigen 'Wesenschau', statt der zweckvollen, sachbestimmten 'Gesellschaft' eine bedingungslose, zweckfreie 'Gemeinschaft an sich'. Folgerichtig liegt das ganze Schwergewicht der Einstellung, im Gegenwurf zu Zweckrationalität und Rechenhaftigkeit, auf irrationaler Emotion."

8 "Die Verdrängung der Lebens- durch die Existenzphilosophie bzw. die Überlagerung der Jugendbewegung durch den Nationalsozialismus findet in dem nahezu völligen Versinken der Dichtung Georges neben der Rilkes eine auffälige Parallele."

\section{BIBLIOGRAFÍA}

Amigo, M. L. (2000): El arte como vivencia de ocio, Bilbao, Universidad de Deusto.

Anderson, N. (1961): Work and Leisure, Nueva York, Free Press.

Bauman, Z. (2002): Modernidad líquida (trad. de M. Rosenberg), Buenos Aires, FCE.

Beck, U. (1986): Risikogesellschaft. Auf dem Weg in eine andere Moderne, Frankfurt a. M., Suhrkamp.

Beck, U.; Giddens, A. y Lash, S. (1994): Reflexive modernization: politic, tradition and aesthetics in the modern social order, Cambridge, Polity.

Bell, D. (1977): Las contradicciones culturales del capitalismo (trad. de N. A. Míguez), Madrid, Alianza.

Bell, D. (1973): The coming of post-industrial society, Nueva York, Basic Books.

Borrie, B. y Roggenbruck, J. (2001): "The dynamic, emergent and multi-phasic nature of on-site wilderness expe- riences", Journal of Leisure Research, 33(2): 202-228.

Briggs, A. y Burke, P. (2002): De Gutenberg a Internet. Una historia social de los medios de comunicación (trad. de M. A. Galmarini), Madrid, Taurus.

Cramer, K.: "Erleben, Erlebnis" en Ritter, J.; Gründer, K. y Gabriel, G. (eds.) (1972): Historisches Wörterbuch der Philosophie (vol. 2), Basilea, Schwabe.

Csikszentmihalyi, M. (1975): Beyond Boredom and Anxiety, San Francisco, Jossey-Bass.

Csikszentmihalyi, M. (1991): Flow: the Psychology of Optimal Experience, New York, Collins.

Cuenca Cabeza, M. (coord.) (2006): Aproximación multidisciplinar a los Estudios de Ocio, Bilbao, Universidad de Deusto.

Cuenca Cabeza, M. (2000): Ocio humanista, Bilbao, Universidad de Deusto.

Dumazedier, J. (1962): Vers une civilization du loisir?, Paris, Les Éditions du Seuil.

Friedmann, G. (1956): Le travail en miettes, Paris, Gallimard.

Gadamer, H. G. (1977): Verdad y método, Tomo I (trad. de A. Agud y R. de Agapito), Salamanca, Sígueme.

Goytia, A. (2008): Los rostros de Ulysses. Modelo para el análisis de turistas en función de la experiencia de ocio, Saarbrücken, Dr. Müller Verlag.

Gumbrecht, H. U. (2006): Elogio de la belleza atlética (trad. de A. Mazzucchelli), Madrid, Katz.

Gumbrecht, H. U. (2004): En 1926. Viviendo al borde del tiempo (trad. de A. Mazzucchelli), Ciudad de México, Universidad Iberoamericana.

Gutiérrez Espada, L. (1979): Historia de los medios audiovisuales, Tomo I, Madrid, Pirámide.

Hull, R.; Stewart, W. y Yi, Y. (1992): "Experience patterns: Capturing the dynamic nature of a recreation experien- ce", Journal of Leisure Research, 24(3): 240-252.

Inglehart, R. (1990): Culture shift in advanced industrial society, Princeton, Princeton University Press.

Iso-Ahola, S. (1980): The Social Psychology of Leisure and Recreation, Dubuque, W. C. Brown.

Jennings, G. R. (1997): "The travel experience of cruisers", en Oppermann, $\mathrm{M}$. (ed.), Pacific Rim 2000: Issues, Interrelations, Inhibitors, London, CAB International, 94-105.

Killion, G. L. (1992): Understanding tourism, Rockhampton, Central Queensland University.

Krockow, Ch. Graf von (1990):, Die Entscheidung. Eine Untersuchung über Ernst Jünger, Carl Schmitt, Martin Heidegger, Frankfurt a. M./New York, Campus.

Lee, Y.; Dattilo, J. y Howard, D. (1994): "The complex and dynamic nature of leisure experience", Journal of Leisure Research, 26: 195-211.

Monteagudo, M. J. (2008): "Reconstruyendo la experiencia de ocio: características, condiciones de posibilidad y amenazas en la sociedad de consumo", en Monteagudo, M. J. (ed.): La experiencia de ocio: una mirada científica desde los Estudios de Ocio, Universidad de Deusto, pp. 81-110.

Neulinger, J. (1974): The Psychology of Leisure, Chicago, Charles Thomas.

Ooi, C. S. (2005): "A theory of tourism experiences: The management of attention", en O'Deli, T. y Billing, P. (eds.): Experiencescapes: Tourism, Culture and Economy, Copenhagen, Copenhagen Business School, 5168.

Ortega y Gasset, J. (2004): "Sobre el concepto de sensación", en Ortega y Gasset, J.: Obras completas, Tomo I, Madrid, Fundación Ortega y Gasset/ Taurus, pp. 624-638. 
Parker, S. (1976): The Future of Work and Leisure, London, Allen \& Unwin.

Riesman, D. (1950): The lonely crowd, New Haven, Yale University Press.

Ritchie, J. R. B. y Hudson, S. (2009): "Understanding and meeting the challenges of consumer/tourist experience research", International Journal of Tourism Research, 11: 111-126.

San Salvador del Valle, R. (2000): Políticas de ocio, Bilbao, Universidad de Deusto.
Schmitt, C. (1991): "La era de las neutralizaciones y las despolitizaciones", en El concepto de lo político (trad. de R. Agapito), Madrid, Alianza.

Smigel, E. (1963): Work and Leisure: a Contemporary Social Problem, New Haven, College and University Press.

Stewart, W. P. (1998): "Leisure as Multiphase Experiences: Challenging Traditions", Journal of Leisure Research, 30(4): 391-400.
Tinsley, H. E. A. y Tinsley, D. J. (1986): "A theory of the attributes, causes and effects of leisure experience", Leisure Sciences (8): 1-45.

Volo, S. (2009): "Conceptualizing experience", Journal of Hospitality Marketing and Management, 18(2-3), 109-127.

Walsmley, J. y Jenkins, J. M. (2003): "Leisure", en Jenkins, J. M. y Pigram, J. J. (eds.), Encyclopedia of Leisure and Outdoor Recreation, London/New York, Routledge. 